\title{
FLOATING DRUG DELIVERY SYSTEM: A INNOVATIVE APPROACH
}

\author{
"Kumar Mukesh, Jha Shubhendra, Singh Shiv Kumar, Mishra Ashutosh kumar, Mrs. Sonia Bhagat \\ Department of Pharmacy, IEC-CET., Plot No.4, Knowledge Park-I, Gr. Noida, U. P., India \\ *Corresponding Author's E-Mail: mukesh7748@gmail.com
}

Received 01 Oct 2012; Review Completed 14 Oct 2012; Accepted 01 Nov 2012, Available online 15 Nov 2012

\begin{abstract}
The current Pharmaceutical scenario focuses on the development of sustained drug delivery systems to achieve required therapeutic concentration with less amount of dose. Several approaches are currently utilized in the prolongation of the gastric residence time including floating drug delivery systems, swelling and expending system, polymeric bio-adhesive systems, high density systems, modified-shape systems and other delayed gastric emptying devices. From the formulation and technological point of view, the floating drug delivery system is comparatively easy and logical approach. Floating drug delivery system is one amongst the GRDFs used to achieve prolonged gastric residence time (GRT). In this review the methods of evaluation of various floating dosage forms and applications of these systems are summarized.

Keywords: Floating drug delivery system (FDDS), Gastric residence time (GRT), Buoyancy
\end{abstract}

\section{INTRODUCTION}

Oral delivery of drugs is the most preferred route of drug delivery due to the ease of administration; low cost of therapy, patient compliance and flexibility in formulation etc. ${ }^{1}$ So the design of oral control drug delivery systems (DDS) should be primarily aimed to achieve more predictable and increased bioavailibility. ${ }^{2}$ Nowadays most of the pharmaceutical scientist is involved in developing the ideal drug delivery system. This ideal system should have advantage of single dose for the whole duration of treatment and it should deliver the active drug directly at the specific site. Scientists have succeeded to develop a system and it encourages the scientists to develop control release systems. Control release implies the predictability and reproducibility to control the drug release, drug concentration in target tissue and optimization of the therapeutic effect of a drug by controlling its release in the body with lower and less frequent dose. ${ }^{3,4}$ It is widely acknowledged that the extent of GIT drug absorption is related to contact time with the intestinal mucosa. Thus, small intestinal transit time is an important parameter for drugs that are incompletely absorbed. ${ }^{5}$ Gastro retentive systems can continue to exist in the gastric region for several hours and hence prolong the period of gastric residence time (GRT) of drugs. The basic idea behind the development of such type of a system, to maintain a constant level of drug in the blood plasma inspire of the fact that the drug dose not undergoes disintegration by which drug usually keeps floating in the gastric fluid and slowly dissolves at a pre-determined rate to release the drug from the dosage form and maintain constant drug levels in the blood. Floating drug delivery systems (FDDS) are aimed to keep possession of the drug in the stomach and useful for poorly or unstable dosage form for those that are less or highly soluble and stable in intestinal fluids. ${ }^{6}$ It is the formulation of a drug and gel forming hydrocolloids meant to remain buoyant on stomach contents. This not only prolongs GI residence time but also does so in an area of the GI tract that would maximize drug reaching its absorption site in solution and hence ready for absorption. ${ }^{7}$ The principal is very simple that the floating of the drug in the stomach occurs due to the low density of the dosage form. Prolonged gastric retention time improves bioavailability, reduces wastage of the drug and improves solubility of those drugs which are less soluble at high $\mathrm{pH}$. It has applications also for local drug delivery to the stomach and proximal small intestines. Gastro retention helps in improving bioavailability of new products with improved therapeutic possibilities and substantial benefits for patients. Based on these approaches, classification of floating drug delivery systems (FDDS) has been described in detail. ${ }^{8}$

\section{Basic Gastrointestinal Tract Physiology}

Basically stomach divided into 3 regions:

1. Fundus: The fundus of the stomach is the left portion of the stomach's body, and is marked off from the remainder of the body by a plane passing horizontally through the cardiac orifice. The rounded part of the upper stomach allows for an accumulation of stomach gases produced by chemical digestion.

2. Body: It also called the corpus and it is an anatomical region of the stomach in humans.

3. Antrum (pylorus): The region of the stomach that connects to the duodenum is the pylorus. It has two parts, the pyloric antrum which connects to the body of the stomach, and the pyloric canal, which leads into the duodenum. 


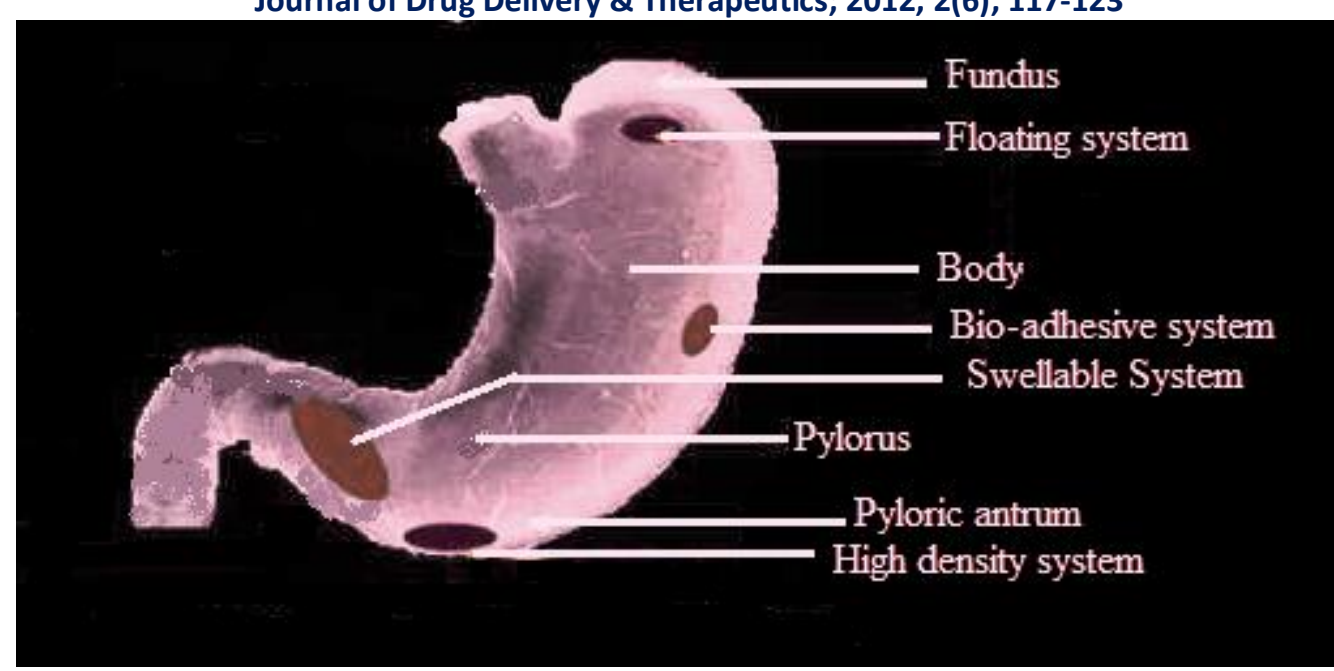

Figure 1 Physiology of Gastrointestinal Tract

The proximal part made of fundus and body acts as a reservoir for undigested material, the antrum is the main site for mixing motions and act as a pump for gastric emptying by propelling actions. ${ }^{9}$ Gastric emptying occurs during fasting as well as fed states. The pattern of motility is however distinct in the two states. During the fasting state an inter-digestive series of electrical events take place, which cycle both through stomach and intestine every 2 to 3 hours. ${ }^{10}$ This is called the inter-digestive migrating myloelectric cycle (MMC).

The inter-digestive migrating myloelectric cycle (MMC) is further divided into 4 phases as described by Wilson and Washington. ${ }^{11}$
Phase I (basal phase) - lasts from 40 to 60 minutes with rare contractions.

Phase II (preburst phase) - lasts for 40 to 60 minutes with intermittent action potential and contractions. As the phase progresses the intensity and frequency also increases gradually.

Phase III (burst phase) - lasts for 4 to 6 minutes. It includes intense and regular contractions for short period. It is due to this wave that all the undigested material is swept out of the stomach down to the small intestine. It is also known as the housekeeper wave.

Phase IV - lasts for 0 to 5 minutes and occur between phases III and I of 2 consecutive cycles.

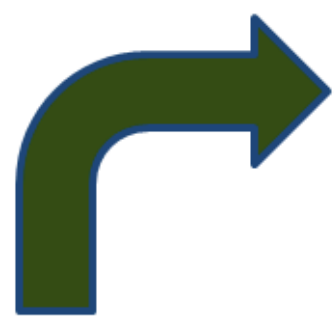

Phase-I (Basal Phase) $30-60 \mathrm{~min}$
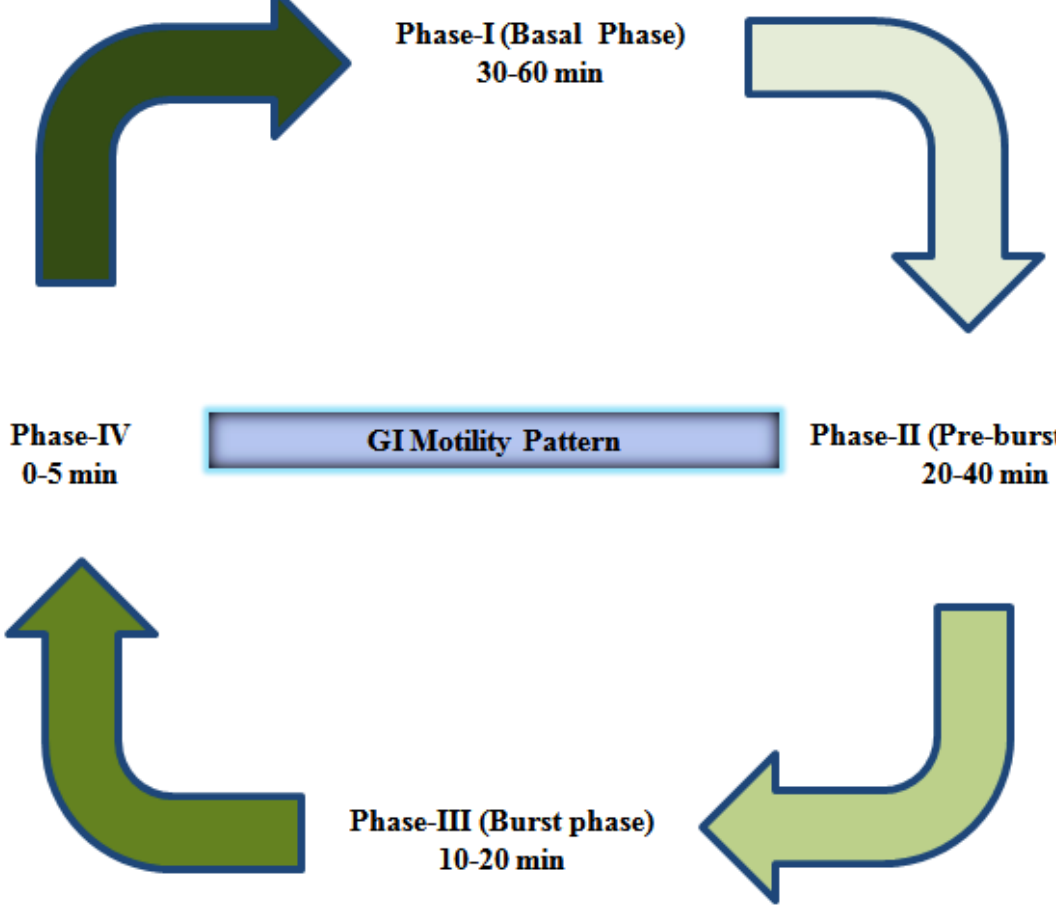

Figure 2: GI motility pattern

After the ingestion of a mixed meal, pattern of contractions changes from fasted state to fed state. This is also known as digestive motility pattern and comprises continuous contractions as in phase II of fasted state.
These contractions result in reducing the food particle size (to less than $1 \mathrm{~mm}$ ), which are propelled toward the pylorus in a suspension form. During the fed state, onset 
of migrating myloelectric cycle (MMC) is delayed that results in slowing down of gastric emptying rate. ${ }^{1,12}$

Scintigraphic studies determine the gastric emptying rates allow to be seen that orally administered GRDFs are subjected to basically two complications, first short gastric residence time and second unpredictable gastric emptying rate.

\section{Classification of Floating Drug Delivery System $^{8}$}

A. Effervescent system

- Gas generating system

- Volatile liquid containing system

B. Non-effervescent System:

- Colloidal gel barrier system.

- Alginate beds.

- Hollow microspheres / Microballons.

- Intragastric Floating Drug Delivery Device / Microporous compartment system

\section{Effervescent Floating Dosage Forms:}

These are matrix types of systems prepared with the help of swellable polymers (methylcellulose and chitosan) and various effervescent compounds (sodium bicarbonate, tartaric acid, and citric acid). They are formulated in such a way that when come in contact with acidic gastric contents, $\mathrm{CO}_{2}$ liberate and gas entrapped in swollen hydrocolloids which provides buoyancy to the dosage forms. $^{13,14}$

\section{Volatile liquid containing systems:}

The GRT of a drug delivery system can be sustained by incorporating an inflatable chamber, which contains a liquid (like ether, cyclopentane), that gasifies at body temperature to cause the inflatation of the chamber in the stomach. The device may also consist of a bio-erodible plug made up of PVA, Polyethylene, etc. that gradually dissolves and causing the inflatable chamber to release gas and collapse after a predetermined time to permit the spontaneous ejection of the inflatable systems from the stomach. $^{15,54}$

\section{Gas-generating Systems:}

These buoyant delivery systems utilize effervescent reactions between carbonate/bicarbonate salts and citric/tartaric acid to liberate $\mathrm{CO}_{2}$, which gets entrapped in the gellified hydrocolloid layer of the systems thus decreasing its specific gravity and making it to float over chyme. $^{2,55}$

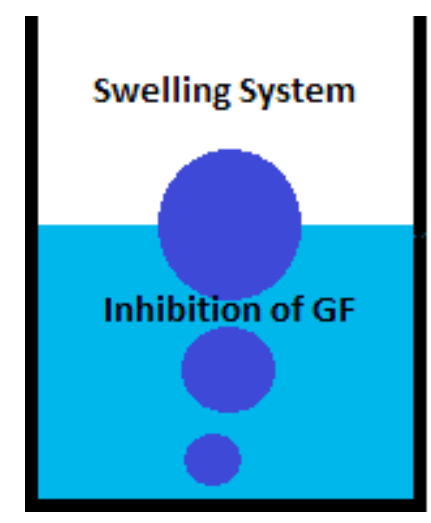

(a)

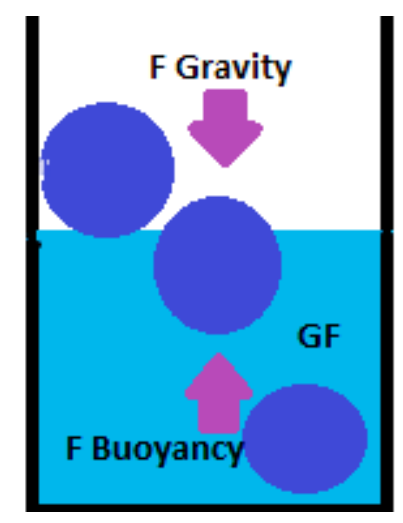

(b)

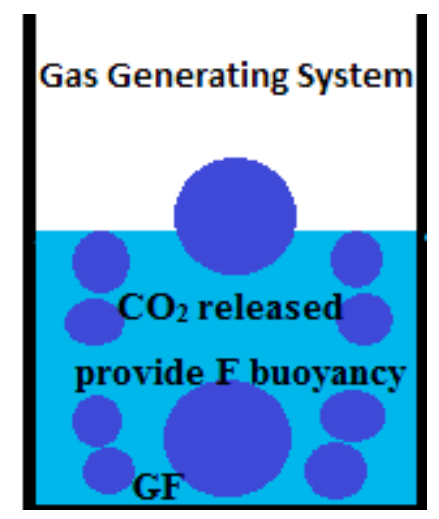

(c)

Figure 3: Mechanism of floating of beads (GF=gastric fluid)

\section{Non-effervescent Floating Dosage Forms:}

The non-effervescent FDDS works on the mechanism of polymer swelling, bioadhesion of the polymer to mucosal layer of GI tract. The most commonly used excipients for the preparations of non-effervescent FDDS are gel forming or swellable cellulose type hydrocolloids, polysaccharides, and matrix-forming polymers like polycarbonate, polyacrylate, polymethacrylate, and polystyrene. The formulation method includes simple approach of thoroughly mixing of the drug and the gelforming hydrocolloid. After oral administration this dosage form swells in contact with gastric fluids and attains bulk density of less than 1. The air entrapped within the swollen matrix imparts buoyancy to the dosage form, so formed swollen gel-like structure acts as a reservoir and allows sustained release of drug through the gelatinous mass. $^{13,15,16}$

\section{Colloidal gel barrier system:}

A system that contains drug with gel-forming hydrocolloids meant to remain buoyant on the stomach content. This prolongs GRT and maximizes the amount of drug that reaches its absorption sites in the solution form for ready absorption. This system incorporates a high level of one or more gel forming highly swellable cellulose type hydrocolloids.e.g. HEC, HPMC, NaCMC, Polysacchacarides and matrix forming polymer such as polycarbophil, polyacrylates and polystyrene, incorporated either in tablets or in capsule. On coming in contact with gastric fluid, the hydrocolloid in the system hydrates and forms a colloidal gel barrier around the gel surface. The air trapped by the swollen polymer maintains a density less than unity and confers buoyancy to this dosage forms. ${ }^{16,54}$

\section{Alginate beads:}

Multi-unit floating dosage forms have been developed from freeze-dried calcium alginate. Spherical beads of approximately $2.5 \mathrm{~mm}$ in diameter can be prepared by dropping sodium alginate solution into aqueous solution 
of calcium chloride, causing the precipitation of calcium alginate. The beads are then separated, snap-frozen in liquid nitrogen, and freeze-dried at $-40^{\circ} \mathrm{C}$ for 24 hours, leading to the formation of a porous system, which can maintain a floating force for over 12 hours. ${ }^{15,16}$

\section{Hollow microspheres / Microballons:}

It is prepared by a novel emulsion solvent diffusion method. The ethanol/dichloromethane solution of the drug and an enteric acrylic polymer was poured into an agitated solution of Poly Vinyl Alcohol (PVA) that was thermally controlled at $40^{\circ} \mathrm{C}$. The gas phase is generated in the dispersed polymer droplet by the evaporation of dichloromethane formed and internal cavity in the microsphere of the polymer with drug. ${ }^{16,17}$

\section{Intragastric / Microporous compartment system:}

The system composed of a drug reservoir encapsulated in a microporous compartment having pores on top and bottom surfaces. The peripheral walls of the reservoir compartment were completely sealed to prevent any physical contact of the undissolved drug with walls of the stomach. ${ }^{17.18}$ Novel levodopa gastro retentive dosage form based on unfolding polymeric membranes which combines extended dimensions with high rigidity. It was folded into a large size gelatin capsules. In vitro studies showed that unfolded form reached within 15 minutes after administration and it was confirmed in vivo in beagle dogs. The unfolded form was maintained for at least 2 hours. It was concluded that this dosage form could improve therapy of different narrow absorption window drugs. However, there are possibilities of the polymeric films to get stuck in the esophagus causing extreme discomfort to the patient or drug related injuries and repeated administration of rigid dosage form may result in gastric obstruction. ${ }^{18,19}$

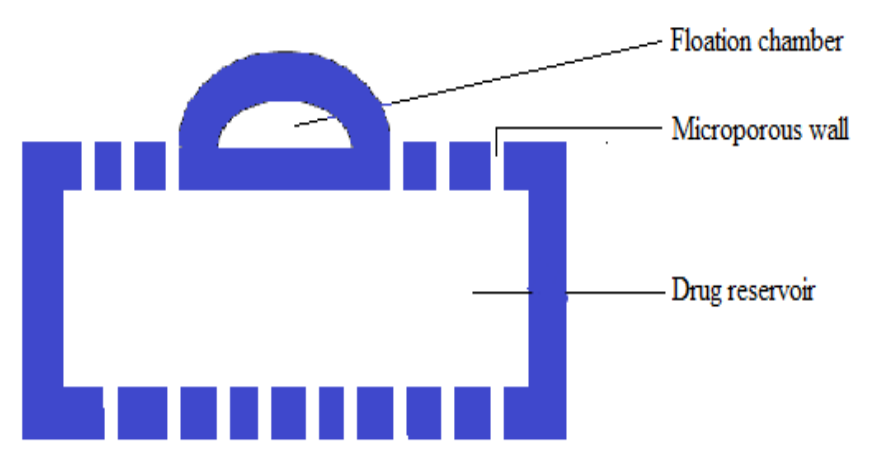

Figure 4: Intra-gastric floating drug delivery device

Table 1: Some materials used for formulation of FDDS

\begin{tabular}{|c|l|l|c|}
\hline S. No. & \multicolumn{1}{|c|}{ Drugs } & \multicolumn{1}{|c|}{ Polymers used } & Ref \\
\hline 1. & Piroxicam & Eudragit S 100 & 20 \\
\hline 2. & Cefpodoxime Proxetil & HPMC K15M, EC & 21 \\
\hline 3. & Furosemide & HPMC 4000,HPMC 100, CMC, Sodium alginate, Xanthum gum & 22 \\
\hline 4. & Ketoprofen & Eudragit RS and Eudragit RL & 23 \\
\hline 5. & Nimodipine & HPMC, PEG-6000, Polaxamer-188 & 24 \\
\hline 6. & Ciprofloxacin & HPMC & 25 \\
\hline 7. & Para-amino benzoic acid & Polyvinyl acetate, Purified shellac & 26 \\
\hline 8. & Paracetamol & PVPK 30, Methyl Cellulose, HPMC (K4M,K15M,K100M) & 27 \\
\hline 9. & Cimetidine & HPMC, Ethyl Cellulose & 28 \\
\hline 10. & Theophyline & Methocel K100M, K15MCR & 29 \\
\hline 11. & Pentoxifilline & HPMC K4M, Sodium CMC, Ac-di-sol & 30 \\
\hline 12. & Verapamil & Cellulose acetate, Eudragit S 100, Acrycoat A 100 & 31 \\
\hline 13. & Celiprolol Hydrochloride & HPMC (K4M,K15M,K100M), Ethyl Cellulose, Polyethylene oxide WSR-60K & 32 \\
\hline 14. & Metformin & HPMC K4M and Ethyl Cellulose & 33 \\
\hline 15. & Stolol Hydrochloride & Sodium carboxy methyl cellulose, Hydroxy propyl cellulose & 34 \\
\hline 16. & Famotidine & Methocel K4M, K15M & 35 \\
\hline 17. & Cephalexine & HPMC K4M, Xanthum gum, Guar gum, Microcrystalline cellulose & 36 \\
\hline 18. & Domperidone Maleate & Xanthum gum, Methocel K4M, K15M, K100LV & 37 \\
\hline 19. & Glipizide & Methocel K4M, Eudragit RS100 & 38 \\
\hline 20. & Nimesulide & HPMC of low and high viscosity, Guar gum, carbapol & 39 \\
\hline
\end{tabular}

\section{ADVANTAGES ${ }^{40,41}$}

- Enhance Bioavailability

- Sustained drug delivery

- Reduce frequency of dosing

- Targeted therapy of local ailments in the upper GIT

- Reduce fluctuation of drug concentration

- Minimize adverse activity colon

DISADVANTAGES ${ }^{42,43}$

- Not feasible for those drugs that have solubility or stability problems in gastric fluids
- Not suitable for the drugs that are irritant to gastric mucosa

- This system requires sufficient high level of fluids in stomach, so that the drug dosage form float therein and work efficiently

- These systems also require the presence of food to delay their gastric emptying

EVALUATION $^{18,28,44-52}$

Determination of the Drug Content: It provides how much amount of the drug that was present in the formulation and should not exceed the limits acquired by 
the standard monographs. Drug content was determined by using spectroscopy techniques HPLC, HPTLC methods, Micro titrimetric methods, Inductively Coupled Plasma Atomic Emission Spectrometer, Near infrared spectroscopy.

\section{A. For Single Unit Dosage Forms (Tablet):}

- Floating lag time and total floating time: It is the time taken by the tablet to emerge on the surface of dissolution medium and expressed in few seconds or minutes. For determination of floating lag time and total floating time, simulated gastric fluid or 0.1 mole. lit $^{-1} \mathrm{HCl}$ (maintained at $37^{\circ} \mathrm{C}$ ) and USP dissolution apparatus containing $900 \mathrm{ml}$ of 0.1 molar $\mathrm{HCl}$ as dissolution medium is used.

- In-vitro drug release and floating duration: This is determined by using USP II apparatus (paddle) stirring on 50 or $100 \mathrm{rpm}$ at $37 \pm 0.2^{\circ} \mathrm{c}$ in simulated gastric fluid ( $\mathrm{pH} 1.2$ without pepsin). Aliquots of the samples are collected and analyzed for the drug content. The time (hrs) for which the tablets remain buoyant on the surface of the dissolution medium is the duration of floating and is visually observed.

- In-vivo evaluation: This is carried out by means of Xray or Gamma scintigraphic monitoring of the dosage form transition in the GIT.

- Content uniformity, hardness, friability: These tests are performed according to specified monographs.

B. For Multiple Unit Dosage Forms (beads, Microspheres):

Apart from the In vitro release, duration of floating and in vivo gastro-retention tests, the multiple unit dosage forms are also evaluated for -

- Particle Size and shape: Dimensional and morphological analysis is carried out with the aid of scanning electron microscopy (SEM), and size can also be measured by optical microscope.

- \% yield of beads: This is calculated from the following formula.

(Weight obtained / Total weight of drug and polymer) $\times \mathbf{1 0 0}$

- In vitro floating ability (Buoyancy \%): A known quantity of microspheres are spread over the surface of a USP (Type II) dissolution apparatus filled with 900 $\mathrm{ml}$ of $0.1 \mathrm{~N} \mathrm{HCl}$ containing $0.002 \% \mathrm{v} / \mathrm{v}$ Tween 80 and agitated at $100 \mathrm{rpm}$ for 12 hours. After 12 hours, the floating and settled layers are separated, dried in a dessicator and weighed. The buoyancy is calculated from the following formula.

\section{$\{\mathbf{W f} /(\mathbf{W f}+\mathbf{W s})\} \times \mathbf{1 0 0}$}

Where Wf and Ws are the weights of floating microspheres and settled microspheres respectively.

- Drug-excipient (DE) interactions: This is done using FTIR. Appearance of a new peak, and/or disappearance of original drug or excipient peak indicate the drug excipient interaction. Apart from the above mentioned evaluation parameters, granules are also evaluated for the effect of ageing with the help of Differential Scanning Calorimeter or Hot stage polarizing microscopy.

- Swelling studies: This is performed to calculate molecular parameters of swollen polymers. It is determined by using Dissolution apparatus, optical microscopy and other sophisticated techniques which include Light scattering imaging (LSI), $\mathrm{H}_{1}$ NMRimaging, Confocal laser scanning microscopy (CLSM), etc. By using Dissolution apparatus (USP dissolution apparatus (USP-24) labindia disso 2000) it is calculated as per the following formula.

\section{Swelling ratio $=$ Weight of wet formulation $/$ Weight of formulations}

- Entrapment efficiency: The drug is extracted by a suitable method, analyzed and is calculated from the following formula.

\section{(Practical amount of drug present / Theoretical drug content) $\times 100$}

\section{APPLICATIONS OF FLOATING DRUG DELIVERY SYSTEMS: ${ }^{43,54-55}$}

- Enhance bioavailability: The bioavailability of CRGRDF is significantly enhanced in comparison to the administration of non-GRDF CR polymeric formulations. There are several different processes, related to absorption and transit of the drug in the gastrointestinal tract, that act concomitantly to influence the magnitude of drug absorption.

- Sustained drug delivery: Oral CR formulations are encountered with problems such as gastric residence time in the GIT. These problems can be overcome with the HBS systems which can remain in the stomach for long periods and have a bulk density $<1$ as a result of which they can float on the gastric contents. ${ }^{42}$ These systems are relatively larger in size and passing from the pyloric opening is prohibited. ${ }^{9},{ }^{55}$

- Site-specific drug delivery systems: These systems are particularly advantageous for drugs those are specifically absorbed from the stomach or the proximal part of the small intestine. ${ }^{55}$ The controlled, slow delivery of drug to the stomach provides sufficient local therapeutic levels and limits the systemic exposure to the drug. It reduces the side effects which are caused by the drug in the blood circulation. In addition, the prolonged gastric availability from a site directed delivery system may also reduce the dosing frequency.

- Absorption enhancement: Drugs which are having poor bioavailability because of site specific absorption from the upper part of the GIT are potential candidates to be formulated as floating drug delivery systems, there by maximizing their absorption. ${ }^{55}$

- Minimize adverse activity at the colon: Retention of the drug in the HBS systems at the stomach minimizes the amount of drug that reaches the colon. Thus, undesirable activities of the drug in colon may be prevented. This pharmacodynamic aspect provides the rationale for GRDF formulation for beta-lactam antibiotics that are absorbed only from the small intestine, and whose presence in the colon leads to the development of microorganism's resistance.

- Reduce fluctuations of drug concentration: Continuous input of the drug following controlled release gastro-retentive dosage form administration produces blood drug concentrations within a narrower 
range compared to the immediate release dosage forms. Thus, fluctuations in drug effects are minimized and concentration dependent adverse effects that are associated with peak concentrations can be prevented. This feature is of special importance for drugs with a narrow therapeutic index.

\section{CONCLUSION}

Drug absorption in the GIT is a highly variable procedure and prolonging GR of the dosage form extends the time for drug absorption. The FDDS become an additional

\section{REFERENCE}

1. Christian V, Ghedia T, Gajjar V. A review on Floating Drug Delivery System as a part GRDDS, IJPRD, 2011; Vol 3(6): 233 241.

2. Chawla G, Gupta P, Koradia V, Bansal AK. Gastroretention: A Means to Address Regional Variability in intestinal drug Absorption, Pharmaceutical technology 2003; Vol-27(2): 50-68.

3. Mathiowitz, Edith RD. Encyclopedia of controlled drug delivery. New York Wiley 1999; Vol-1: 9-11.

4. Shivkumar HG, Gwdaand DV, Kumar PTM. Floating Controlled Drug Delivery Systems For Prolong Gastric Residence, Indian.J.Pharm.Educ. 2004; Vol-38(4): 172-179.

5. Hirtz J. The git absorption of drugs in man: a review of current concepts and methods of investigation. Br J Clin Pharmacol. 1985; 19:77S-83S

6. Reddy LH, Murthy RS. Floating dosage systems in drug delivery. Crit. Rev. Ther. Drug Carr. Syst., 2002; 19: 553-585.

7. Dolas RT, Hosmni A, Bhandari A, Kumar B, Somvanshi S. Novel sustained release gastroretentive drug delivery system: A review. IJPRD 2011; Vol-2(11): 26-41.

8. Chandel A, Chauhan K, Parashar B, Kumar H, Arora S Floating drug delivery systems: A better approach. International Current Pharmaceutical Journal 2012; 1(5): 110-118.

9. Desai S. A Novel Floating Controlled Release Drug Delivery System Based on a Dried Gel Matrix Network, Jamaica, NY: St John's University, 1984.

10. Vantrappen GR, Peeters TL, Janssens J. The secretory component of inter-digestive migratory motor complex in man. Scand J Gastroenterol. 1979; 14: 663-667.

11. Wilson CG, Washington N. The stomach: its role in oral drug delivery. In: Rubinstein MH, ed. Physiological Pharmaceutical: Biological Barriers to Drug Absorption. Chichester, UK: Ellis Horwood, 1989; 47-70.

12. Desai, S, Bolton S. A floating controlled release drug delivery system: in vitro- in vivo evaluation. Pharm Res (1993); 10(9) 1321-1325.

13. Arora S, Javed Ali Khar KR, Ahuja A. Floating drug delivery system: A Review. AAPS PharmSciTech 2005; 06(03).

14. Rubinstein A, Friend DR. Specific delivery to the gastrointestinal tract, in: A. J. Domb (Ed.), Polymeric site- specific Pharmacotherapy, Wiley, Chichester, 1994; 282-283.

15. Vyas SP, Roop KK. Controlled DrugDelivery Concepts and Advances, First Edition, New Delhi. 2002; 196-217.

16. Jain NK. Progress in Controlled and Novel Drug Delivery Systems. First Ed. CBSS.Gopalakrishnan et al,Journal of Pharmaceutical Science and Technology. Publishers and Distributors, New Delhi,Bangalore. 2004; 3(2): 84-85.

17. Goyal M, Prajapati R, Purohit KK, Mehta SC. Floating drug delivery system, Journal of current pharmaceutical research 2011 ; 5(1): 7-18.

18. Klausner EA, Sara E, Lavy E, Friedman M, Hoffman A. Novel levodopa gastro-retentive dosage form: in-vivo evaluation in dogs. J. Control. Release, 2003; 88:117-126.

19. Kale RD, Tayade PT. A multiple unit floating drug delivery system of Piroxicam using Eudragit polymer. Indian J PharmScie 2007; 69(1): 120-123.

20. Deepaa MK, Karthikeyanb M. Cefpodoxime proxetil floating microspheres: Formulation and in vitro evaluation. Iran J Pharm Sci 2009; 5: 69-72. advantage for drugs that are absorbed primarily in the upper part of GI tract, i.e., the stomach, duodenum, and jejunum. Floating drug delivery systems have emerged as an efficient means of enhancing the bioavailability controlled delivery of many drugs. FDDS promises to be a potential approach for gastric retention. Although there number of difficulties to be solved out to achieve prolonged gastric retention. Inspite of its various limitations serious efforts are being done to commercialize this delivery system.

21. Ozdemir N, Ordu S, Ozkan Y. Studies of floating dosage forms of furosemide: in vitro and in vivo evaluation of bilayer tablet formulation. Drug Dev Ind Pharm 2000; 26: 857-866.

22. El-Kamal AM, Sokar MS, Al Gamal SS, Naggar VF. Evaluation of stomach protective activity of ketoprofen floating microparticles. Indian J Pharm Sci 2003; 65: 399-41.

23. Wu W, Zhou Q, Zhang HB, Ma GD, Fu CD. Studies on nimodipine sustained release tablet capable of floating on gastric fluids with prolonged gastric resident time. Yao Xue Xue Bao 1997; 32: 786-790.

24. Basak SC, Nageshwara RK, Manavalan R, Ramarao P. Development and in-vitro evaluation of an oral floating matrix tablet formulation of ciprofloxacin. Indian J. Pharm Sci 2004; 66: 313-316.

25. Ichikawa M, Watanabe S, Miyake Y. A new multiple unit oral floating dosage system, preparation and in vitro evaluation of floating and sustained - release kinetics. J Pharm Sci 1991; 80 1062-1066.

26. Sahni JK, Ahmed FJ, Ahuja A, Khar RK. Formulation and evaluation of Hydrodynamically system of Paracetamol. The Indian Pharmacist 2007; (55): 99-101.

27. Srivastava AK, Ridhurkar DN, Wadhwa S. Floating microspheres of cimetidine: Formulation, characterization and in vitro evaluation. Acta Pharm 2005; 55: 277-285.

28. Khan F, Razzak MS, Khan MZ, Azad MA, Chowdhury JA, Reza MS. Theophylline loaded gastroretentive floating tablets based on hydrophilic polymers: Preparation and in vitro evaluation. Pak J Pharm Sci 2009; 22: 155-61.

29. Baumgartner S, Julijana K, Vercez F,Vadopivee P, Jorko B. Optimization of floating matrix tablets and evaluation of their gastric residence time, Int J Pharm 2000; 195: 125-135.

30. Tanwar YS, Naruka PS, Ojha GR. Development and evaluation of floating microspheres of verapamil hydrochloride. Br J Pharm Sci 2007; 43: 529-33.

31. Quereshi MJ, Ali T, Ahuja A, Baboota S. Formulation strategy for low absorption window Anti-hypertensive agent. Indian J Pharm Scien 2007; 69(3): 360-364.

32. Ali J, Arora S, Ahuja A, Babbar AK, Sharma RK, Khar RK. Formulation and development of hydrodynamically balanced system for metformin: In vitro and in vivo evaluation. Eur J Pharm Biopharm 2007; 67: 196-201.

33. Jimenez RM, Castellanos, Zia H, Rhodes CT. Design and testing invitro of bioadhesive and floating drug delivery system for oral application. Int J Pharm 1994; 105: 65-70.

34. Jaimini M, Rana AC, Tanwar YS. Formulation and evaluation of floating tablet of Famotidine. Current Drug Delivery 2007; 4: 51 55.

35. Rao BP, Kottan NA, Snehith VS, Ramesh C. Development of gastro retentive drug delivery system of cephalexin by using factorial design. ARS Pharm 2009; 50: 8-23.

36. Bhalero AV, Riswalkar PV, Deshkar SS, Shirolkar SV, Deshpandey AD. Formulation and evaluation of Domperidone maleate floating drug delivery system. The Indian Pharmacist 2008; 77: 93-100.

37. Prabhu P, Nayari HM, Gulzar AM, Yadav B, Narayana CNR, Satyanarayana D, Subrahmanyam. Formulation and invitro evaluation of gastric oral floating tablet of Glipizide, Indian J Pharm Educ Res 2008; 42(2): 174-183. 
38. Jangde R, Gorde N, Hargude S, Saraf S, Saraf S. Monolithic floating tablets of Nimisulide, The Phamaceutical Magazine 2008; $1-3$.

39. Babu VBM, Khar RK. In vitro and In vivo studies of sustained release floating dosage forms containing salbutamol sulphate. Pharmazie (1990); 45: 268-270.

40. Kikani HN. A Thesis on, Floating Drug Delivery System,The North Gujarat University, Patan 2001, 11-12.

41. Narang N. An Updated Review on: Floating Drug Delivery System (FDDS), International Journal of Applied Pharmaceutics, 2011; Vol. 3: 1-7.

42. Mayavanshi AV, Gajjar SS. floating drug delivery systems to increase gastric retention of drugs: A review, Research J. Pharm. And Tech., 2008; 1(4): 345-348.

43. Khan AD, Bajpai M. Floating Drug delivery system: An Overview, Int.J. PharmTech Res, 2010; Vol. 2(4): 2497-2505.

44. Sharma S, Prashar M, Sahu RK. Floating drug delivery system: Incredible revolution, Pharmacologyonline 3; 2011; 1039-1054.

45. Baumgartner S, Kristl J, Vrecer F. Optimization of floating matrix tablets and evaluation of their gastric residence time. Int J Pharm 2000; 195: 125-135.

46. Sharma M, Chaturvedi AK, Singh UK, Gupta RD, Gulati A, Sehgal P. Floating drug delivery system : An approach to oral controlled drug delivery. The pharma research, vol. 7; Issue 1: 114.

47. Liu, X, Zhang Y, Tang X, Zhang H. Determination of entrapement efficiency and drug phase distribution of submission emulsions loaded silybin. Journal of microencapsulation 2009; 26, 2: 180186.

48. James S. Encyclopedia of pharmaceutical technology, Edition-3; Vol-6: 36-44.

49. Panna T, Howard NES, Alan J, Baillie. In vitro drug release studies from a novel Lyophilized nasal dosage form, Katmandu university journal of science, engineering and technology, 2009; 5: 71- 86.

50. Sahni J, Raj S, Ahmad FJ, Khar RK. Design and in vitro characterization of buccoadhesive drug delivery system of insulin, 2008; 70: 61-65.

51. Khan F, Millat S, Razzak I, Khan ZR, Azam K, Sadat SMA, Reza S. Preparation and invitro Evaluation of Theophylline loaded Gastroretentive Floating tablets of Methocel K4M, J. Pharm. Sci. 2008; vol. 7(1): 65-70.

52. Umamaheswari RB. A new approach in gstroretentive drug delivery system using cholestyramine, Drug delivery 2003; 10: 151-160.

53. Patel GM. Floating Drug Delivery System : An Innovative Approach to Prolong Gastric Retention, pharmainfo.net 2007

54. Sangekar S. Evaluation of effect of food and specific gravity of the tablets on gastric retention time, Int.J.Pharm, 1987; Vol-35(3): 3453.

55. Moursy NM, Afifi NH, Ghorab DM, El-Saharty Y. Formulation and evaluation of sustained release floating capsules of Nicardipine hydrochloride, Pharmazie, 2003; 58: 38-43. 